\title{
Influence Hybrid Fillers on Electrical and Mechanical Properties of Fiber Reinforced Epoxy Composites
}

\author{
Santhy P Kuruvilla ${ }^{1,2}$ \\ ${ }^{1}$.JSS Research Foundation, \\ JSS Technical Institute Campus, Mysuru, India \\ 2. Dept. of Electronics and Communication, Maharaja Institute of Technology, \\ Mysuru, India
}

\author{
N. M. Renukappa ${ }^{3 *}$ \\ 3. Dept. of Electronics and Communication, \\ JSS Science and Technology University, \\ Mysuru, India
}

\author{
J. Sundara Rajan ${ }^{4}$ \\ 4. Consultant. Insulation Engineering and \\ Academic Counsellor \\ Bengaluru 560070, India
}

\begin{abstract}
Fiber reinforced epoxy nano-composites have replaced the conventional polymer composites for their inherent advantages. However, in the use of nano-composites for $\mathrm{HV}$ insulation, several challenges are faced in achieving a proper balance of electrical, thermal and mechanical characteristics. Improvements in the properties of the composites have been achieved by combination of nano and micron sized fillers. This paper considers the merits of combining micro and nano fillers in an epoxy matrix with glass fiber reinforcement to demonstrate that such hybrid composites would provide better alternatives to the conventional epoxy nano-composites. Nano silica and nano alumina fillers have been combined with three micro-fillers namely Magnesium oxide, Calcium carbonate and ATH to form hybrid composites and their performance is compared with that of the base glass epoxy composite. The improvements in few electrical and mechanical properties have been discussed in this paper.
\end{abstract}

Keywords-Composite insulation; epoxy resin; dielectric breakdown; surface treatment; nanotechnology; dielectric measurement

\section{INTRODUCTION}

The use of a combination of inorganic fillers in polymer composites has been investigated to overcome the disadvantages of a single filer in a polymer matrix [1-4]. When more than one filler or fiber is used, the composites are referred to as hybrid composites. A hybrid polymer composite is thus a multi-component system, consisting of a matrix phase reinforced with more than one filler or fiber which is not similar in all respects.

The use of two or more filler reinforcements in a polymer matrix or the use of multiple matrices also results in the formation of hybrid polymer composites. Hybridization results in a more stable formation by improving the crosslinking which helps to achieve a certain desired property which is not otherwise achievable. Hybridization provides additional degree of freedom to develop high performance composites by virtue of the contrasting properties of the filler materials. However, the characteristics of hybrid composites are governed by a more complex nature of the resulting interfacial properties of the fillers and the method of fabrication deployed.

The important expectations from successful hybridization of fillers are the economic advantages that accrue due to the incorporation of expensive filler in very small percentage in an inexpensive polymer matrix and achievement of a broader range of properties, which may be physical, mechanical, thermal or dielectric parameter or a proper balance of all desirable characteristics. The inability of engineering materials to possess all desirable properties has led to the use of hybrid composites in which small percentages of nano and micro fillers are used to overcome the deficiencies of the polymer and for maintaining a proper balance of different parameters.

Inorganic fillers with sizes of the order of few nano meters to tens of nano meters are considered under the broad category of nano fillers. The nano fillers considered in this investigation are alumina and silica. Silica improves the thermal and flexural properties of the composites. But the disadvantage of silica fillers is that the dynamic mechanical properties are affected. Alumina fillers are useful for minimizing the impact damage of the composites. The fillers are used in very low concentrations, not exceeding $10 \mathrm{wt}$ \% for optimal benefits, but even higher percentages of fillers have been used.

The inorganic fillers of the size of few $\mu \mathrm{m}$ to tens of $\mu \mathrm{m}$ is broadly classified under micro-fillers. The micro-fillers considered in this investigation are Alumina Trihydrate, Calcium carbonate, and Magnesium Oxide.

ECR glass fiber of $75 \mathrm{wt} . \%$ was used as the reinforcement for the base MY 740-epoxy resin matrix. The wt. \% of the base resin was varied from 10 to $25 \%$ and the combination of nano and micro fillers was accommodated by the reduction in 
the weight percentage of the base epoxy. The variations in the weight percentages of epoxy and the fillers were mandated by the need for achieving optimum and balanced properties of the composites [5-7].

This investigation was carried out to highlight the advantages of hybrid fillers for high voltage insulation applications. The benefits of the individual fillers are the main criterion for combining the nano and micron sized fillers. Initially the weight percentage of fillers in the hybrid composites was varied and optimized by prior experimentation [5-7]. The range of filler weight percentages used were based on literature reports and the benefits that accrue are very specific to the base matrix, the purity and properties of the individual fillers, their pretreatment processes and the method of fabrication employed. In order to bring out the advantages of the hybrid combination of fillers in glass epoxy composites, representative results of electrical and mechanical properties of the composites have been presented and discussed.

\section{EXPERIMENTAL METHOD}

\section{A. Materials}

The method of fabrication of the epoxy and filled epoxy composites is the key for successful development of hybrid composites. The most important process, which is critical is the functionalization of the ECR glass fiber and the nanofillers, and the pultrusion method of fabrication. The details of the fabrication method employed are discussed in earlier publications [5-7]. The details of the resin, hardener and fillers used in the fabrication are shown in Table I and Table II.

\section{B. Fabrication}

The epoxy resin with surface functionalized long ECR-glass fiber (3-glycidyloxypropy) were used in the fabrication of the epoxy and epoxy hybrid composites. The nano-fillers were subjected to surface functionalization. The two nano-fillers were included for imparting better electrical and mechanical properties and the micro-fillers were incorporated for achieving a proper balance of the properties of the composites [5-7].

TABLE I. DETAILS OF MATERIALS USED IN FABRICATION OF COMPOSITES

\begin{tabular}{|c|c|c|c|}
\hline No & Materials & Source & $\begin{array}{l}\text { Density } \\
\left(\mathrm{g} / \mathrm{cm}^{3}\right)\end{array}$ \\
\hline 1 & Epoxy (MY740) & \multirow{3}{*}{$\begin{array}{l}\text { Huntsman, } \\
\text { USA }\end{array}$} & 1.16 \\
\hline 2 & Hardener (HY918) & & 1.2 \\
\hline 3 & $\begin{array}{l}\text { Accelerator } \\
\text { (DY062) }\end{array}$ & & 0.9 \\
\hline 4 & $\begin{array}{l}\text { ECR glass fiber } \\
(18 \mathrm{~nm})\end{array}$ & $\begin{array}{l}\text { Owens } \\
\text { Corning, India }\end{array}$ & 2.62 \\
\hline 5 & Alumina $(12 \mathrm{~nm})$ & \multirow{4}{*}{$\begin{array}{l}\text { Sigma Aldrich, } \\
\text { USA }\end{array}$} & 4.0 \\
\hline 6 & Silica $(12 \mathrm{~nm})$ & & 2.6 \\
\hline 7 & $\mathrm{CaCO} 3(5 \mu \mathrm{m})$ & & 2.9 \\
\hline 8 & $\mathrm{MgO}(8 \mu \mathrm{m})$ & & 3.6 \\
\hline 9 & ATH $(2.6 \mu \mathrm{m})$ & $\begin{array}{l}\text { Akrochem } \\
\text { Corp. }\end{array}$ & 2.4 \\
\hline
\end{tabular}

\section{Measurement}

The parameters evaluated have been broadly grouped under electrical and physico-mechanical parameters. The method followed in the measurements is briefly discussed. Since density is an important parameter, density was measured experimentally and theoretically to estimate the void fraction of the composites

TABLE II. DETAILS OF THE COMPOSITES

\begin{tabular}{|l|l|}
\hline \multicolumn{1}{|c|}{ Composite } & \multicolumn{1}{c|}{ Description } \\
\hline GE & ECR glass fiber reinforced (78) epoxy (22) \\
\hline GESAA & $\begin{array}{l}\text { ECR glass fiber (75) reinforced epoxy (15) with } \\
\text { nano-silica (2) + nano alumina (3) +micro ATH (5) }\end{array}$ \\
\hline GESAC & $\begin{array}{l}\text { ECR glass fiber (75) +epoxy (15) + nano silica (2) } \\
+ \text { nano alumina (3) + micro } \mathrm{CaCO}_{3}(5)\end{array}$ \\
\hline GESAM & $\begin{array}{l}\text { ECR glass fiber (75) + epoxy (15) + nano silica (2) } \\
\text { +nano alumina (3) + micro } \mathrm{MgO}(5)\end{array}$ \\
\hline
\end{tabular}

\section{(i) Contact Angle}

For measurement of contact angle of the composites, methods suggested in ASTM D 724 and ASTM D5946 were used. Contact angle measurements on the surface of insulating material are usually carried out to determine the surface properties of the materials like hydrophobic or hydrophilic nature and the surface energy. Hollmarc make contact angle apparatus was used for measurements. The samples were oriented so that the surface under consideration was horizontal. Water drop was carefully placed on the horizontal surface of the sample with the help of a needle of a hypodermic syringe. The drops were photographed with the help of high-resolution digital camera immediately after the placement of the water drop on sample. The data was then analyzed using software "ImageJ". The drop volume was controlled to be within $2 \mu \mathrm{L}$, and the time set was 100 seconds. For each specimen, the contact angle was measured at five different locations and the average value was considered for assessment and analysis. The surface energy parameters were computed based on measurement of CA with water and formamide and the method was based on guidelines followed in literature [7]. Surface energy parameters namely work of adhesion (WA), Interfacial Free energy (IFE), spreading coefficient (SC) and Interaction parameter $(\phi)$ were computed and the corresponding values of the composites have been compared.

\section{(ii) Electrical Parameters}

All the measurements were carried out under standard laboratory conditions of $25 \pm 5^{\circ} \mathrm{C}$ and $\mathrm{RH}$ of $55 \pm 5 \%$. For measurement of electric strength ASTM D149 was followed. For dielectric constant and dissipation factor, method outlined in ASTM D 150-98, for volume and surface resistivity ASTM D257-91, for comparative tracking index IEC-60112 and ASTM D2303-97 for Inclined plane tracking and erosion were adopted.

\section{(iii) Physico-Mechanical Parameters}

The density of the composites was determined in accordance with ASTM D792 specification. The mechanical measurements carried out were Tensile strength and Modulus 
(ASTM D 638 M-93), Shore-D Hardness (ASTM D2240-00) and Compression strength (ASTM D 690).

\section{RESULTS AND DISCUSSION}

The role of nanofillers and combined micro and nanofillers on the properties of the composite namely $\mathrm{CA}$, tracking and erosion, dielectric strength, dielectric and dissipation factor, resistivity, density, hardness, tensile, compression strength and dynamic mechanical properties under thermal loading are discussed.

\section{A. Effect of Hybrid Fillers on Contact Angle}

From the investigations on the microstructure, it is established that there is decrease in all the critical nano-size parameters. Hence the effect of hybridization on the initial contact angle (CA) and contact angle after $1000 \mathrm{~h}$ of immersion in tap water is shown in Table III. It is observed that the contact angle of the composites increases considerably due to incorporation of nano fillers and a combination of nano and micro-fillers. The work of adhesion (WA), Interfacial Free energy (IFE), spreading coefficient (SC) and Interaction parameter $(\phi)$ show identical trends in variation with addition of nano fillers and combination of nano and micro-fillers, which is a clear sign of improvement in the wetting characteristics of the composites, resulting from the tortuous water diffusion pathway formed due to the combination of the fillers.

TABLE III. CA AND SURFACE ENERGY PARAMETERS OF THE COMPOSITES.

\begin{tabular}{|c|c|c|c|c|c|c|}
\hline \multirow[b]{2}{*}{$\begin{array}{c}\text { Composi } \\
\text { te }\end{array}$} & \multirow{2}{*}{$\begin{array}{l}\mathrm{CA} \\
\left({ }^{\circ}\right)\end{array}$} & \multirow{2}{*}{$\begin{array}{c}\text { Surface } \\
\text { energy } \\
\left(\mathrm{mJ} / \mathrm{m}^{2}\right)\end{array}$} & \multicolumn{4}{|c|}{ Surface energy parameters } \\
\hline & & & $\begin{array}{c}\text { WA } \\
\left(\mathrm{mJ} / \mathrm{m}^{2}\right)\end{array}$ & $\begin{array}{c}\mathrm{IFE} \\
\left(\mathrm{mJ} / \mathrm{m}^{2}\right)\end{array}$ & $\underset{\left(\mathrm{mJ} / \mathrm{m}^{2}\right)}{\mathrm{SC}}$ & $\phi$ \\
\hline GE & 86 & 51.00 & 77.9 & 45.9 & -67.6 & 0.63 \\
\hline GEA & 92 & 42.76 & 71.0 & 49.2 & -75.0 & 0.62 \\
\hline GESA & 95 & 38.80 & 68.2 & 51.2 & -80.1 & 0.61 \\
\hline GESAA & 100 & 44.50 & 60.2 & 57.0 & -85.3 & 0.49 \\
\hline GESAC & 110 & 37.15 & 47.9 & 61.9 & -97.6 & 0.39 \\
\hline GESAM & 118 & 31.80 & 38.6 & 65.9 & -106.9 & 0.31 \\
\hline
\end{tabular}

\section{B. Contact Angle of the composites after water immersion}

The variations in CA of composites as a function of time duration when immersed in water is shown in Fig. 1(a). In all the materials, it is observed that the CA decreases due to diffusion of water into the bulk of the composites. However, it is interesting to observe that two distinct minima of the CA are seen, one at $50 \mathrm{~h}$ and the other at $150 \mathrm{~h}$ respectively. The $50 \mathrm{~h}$ minimum of $\mathrm{CA}$ is seen in GE, GESAA and GESAC. Further, GESAC has an additional CA minimum at $150 \mathrm{~h}$ while in GESAM, the minimum of CA is only observed at $150 \mathrm{~h}$. The $50 \mathrm{~h}$ minimum of $\mathrm{CA}$ is attributed to the water absorption of the epoxy matrix with glass fibers in $\mathrm{GE}$ and GESAA. However, in GESAC, both the base matrix and the filler have a role in water absorption characteristics. Once the saturation level of water is reached in the epoxy matrix, water absorption continues into the space between the filler particles and the free volume. The tortuous water diffusion pathway is responsible for the requirement of longer duration for the occurrence of the second minima of CA. These results confirm the existence of different zones of water as discussed by some authors, in nano composites [8]. The occurrence of $\mathrm{CA}$ minimum at $150 \mathrm{~h}$ leads to the conclusion that the size of the micro-filler particle is crucial factor which determines the existence of water in free volume of the hybrid composites. Thus, GESAM appear to be relatively better in this aspect, followed by GESAC.

To probe further, the composites were immersed in water for different durations to achieve a starting CA of $80^{\circ}$. The composites were placed in a controlled environment having a temperature $25 \pm 2^{\circ} \mathrm{C}$ and $55 \pm 5 \% \mathrm{RH}$. The ability of the materials to regain $\mathrm{CA}$ with time duration was studied and the results are shown in Fig. 1(b). Since water absorption/desorption is a temperature dependent mechanism, it was intended to evaluate the ability of composites to give up the loosely bound water. The maximum gain in CA is seen with in $200 \mathrm{~h}$ in all the composites. GESAM, shows the ability for the CA to reach level of $112^{\circ}$ as compared to $118^{\circ}$ of virgin composite, while GESAA reaches a level of $95^{\circ}$ as compared to $100^{\circ}$ of the virgin composite. In GESAC, the recovery is up to $93^{\circ}$ as compared to $110^{\circ}$ of the virgin composite and the $\mathrm{CA}$ of $\mathrm{GE}$ reaches $85^{\circ}$, which is only slightly below CA value of virgin composite. Thus, it is evident that the water zone model that exists in a nano composite is determined by the distribution pattern of the nano and micro fillers within the epoxy matrix.

Long-duration drift in the absorption kinetics of polymers is seen during uptake of water. This is controlled by the viscoelastic relaxation of the polymer chains [7]. From the results of water absorption, it is also established that GE, GESAA GESAC and GESAM follow the Fickian diffusion mechanism up to 70-72 \% in GE and it gradually increases to $87 \%$ in GESAA, $89 \%$ in GESAC and $91 \%$ in GESAM. The balance of the diffusion mechanism is observed to follow the non-Fickian or the anomalous type of diffusion [7].

The relative decrease in water absorption of epoxy is attributed to the increase of tortuosity of the path of water penetration due to the hybridization of ECR glass fiber, nano$\mathrm{Al}_{2} \mathrm{O}_{3}$, nano- $\mathrm{SiO}_{2}$ and the presence of $\mathrm{MgO}$. The ECR glass surface treated with silane leads to good interaction between epoxy and fiber and reduces water uptake. Further, the incorporation of fillers, reduces the volume of the voids and hence accommodation of water is restricted. The strong interface between epoxy, ECR glass fiber and fillers is responsible for reduction in water absorption in GESAM.

The one of the serious limitations of the polymer composites for both indoor and outdoor applications is their susceptibility to tracking and erosion under wet contaminated conditions. The results of Comparative Tracking index (CTI) of the composites are shown in Table IV. Though the CA of virgin materials with filler is higher, the materials are rendered hydrophilic at the end of CTI test in case of base GE material In case of GESAA, the material remains at the lower end of hydrophobic range. The other three materials continue to be hydrophobic in nature. 


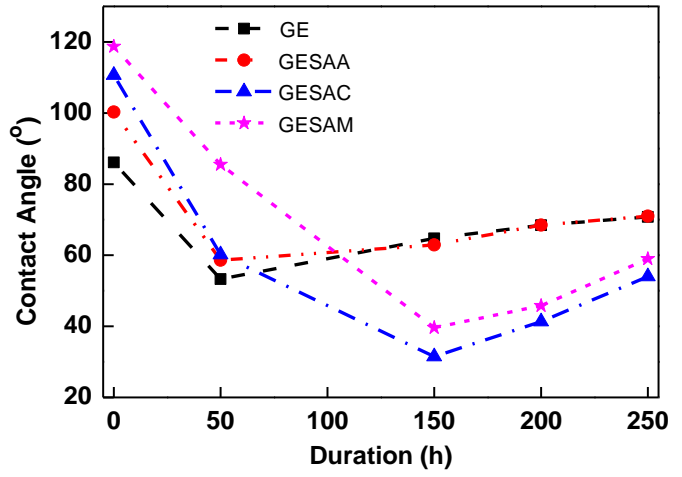

(a)

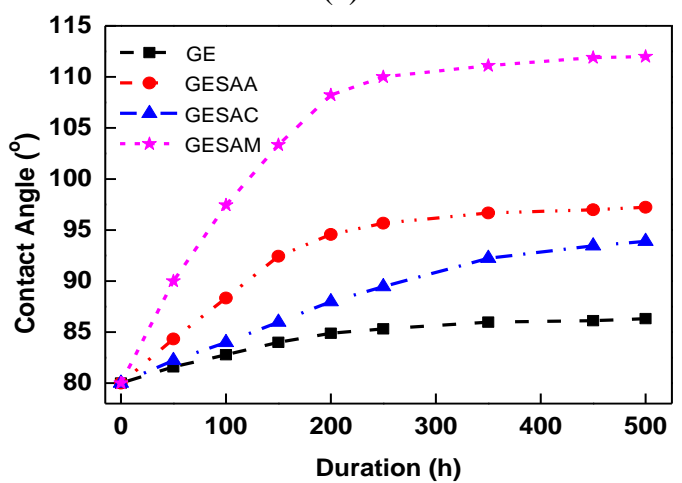

(b)

Fig. 1(a) Variations in Contact angle after immersion in $\mathrm{NaCl}$ solution of conductivity for $250 \mathrm{~h}$. (b) Recovery of hydrophobicity of composites with a starting CA of $80^{\circ}$

\section{Effect of hybrid filler on tracking and erosion}

The CTI of the composites did not show much difference and it was difficult to distinguish the ability of the composites to resist surface tracking when IEC 112 method "A" was used as can be seen from the results of Table IV. Hence evaluation by method B of IEC 112 was undertaken, and the results are shown in Table V. The CTI of the base composite is reduced to 550 , but the values of the hybrid composites are unaffected.

TABLE IV. CTI OF THE COMPOSITES BY METHOD “A” OF IEC 112

\begin{tabular}{|c|c|c|c|}
\hline \multirow{2}{*}{ Composite } & \multirow{2}{*}{ CTI } & \multirow{2}{*}{$\begin{array}{l}\text { Range of depth } \\
\text { of erosion }(\mathrm{mm})\end{array}$} & $\mathrm{CA}\left({ }^{\circ}\right)$ \\
\hline & & & After CTI test \\
\hline GE & 600 & $0.11-0.13$ & $60-65$ \\
\hline GESAA & 600 & $0.09-0.11$ & $90-92$ \\
\hline GESAC & 600 & $0.07-0.09$ & $95-98$ \\
\hline GESAM & 600 & $0.07-0.09$ & $96-99$ \\
\hline
\end{tabular}

The results of Inclined plane tracking and erosion of the composites are shown in Table VI. The composites withstood proof voltage of $6 \mathrm{kV}$ for $6 \mathrm{~h}$, but there are differences in the depth of erosion. Though tracking is not initiated in any of the composites, the base epoxy composite suffered higher depth of erosion. Tracking is reported to improve with Alumina fillers [ 8] due to better cross linking resulting from silane treatment. Further improvements in tracking resistance is seen when nano fillers are combined with the micro filler.

\section{Effect of fillers on the Dielectric Strength}

The results of the $50 \mathrm{~Hz}$ AC electric strength of the composites across $3 \mathrm{~mm}$ thick samples which were evaluated for the flat wise (across the thickness) and edgewise electric strength (across the surface) are shown in Table VII.
TABLE V. CTI VALUES OF THE COMPOSITES BY METHOD “B” OF IEC 112

\begin{tabular}{|l|l|l|l|}
\hline Composite & CTI & \multicolumn{1}{|c|}{$\begin{array}{c}\text { Average } \\
\text { Depth of } \\
\text { erosion }(\mathbf{m m})\end{array}$} & $\begin{array}{c}\text { CA at the end } \\
\text { of CTI test }\end{array}$ \\
\hline GE & 550 & $0.20-0.25$ & $55-60$ \\
\hline GESAA & 600 & $0.10-0.15$ & $80-90$ \\
\hline GESAC & 600 & $0.10-0.14$ & $90-92$ \\
\hline GESAM & 600 & $0.10-0.13$ & $90-98$ \\
\hline
\end{tabular}

TABLE VI. TIME TO TRACK AT A VOLTAGE OF 6 KV FOR 6 H

\begin{tabular}{|l|l|l|l|}
\hline Composite & $\begin{array}{c}\text { Time for track } \\
\text { initiation }(\mathbf{h})\end{array}$ & $\begin{array}{c}\text { Depth of } \\
\text { erosion }(\mathbf{m m})\end{array}$ & $\begin{array}{c}\text { CA after } \\
\text { the test }\end{array}$ \\
\hline GE & No Tracking & $0.20-0.25$ & $48-52$ \\
\hline GESAA & No Tracking & $0.10-0.15$ & $80-90$ \\
\hline GESAC & No Tracking & $0.08-0.12$ & $86-93$ \\
\hline GESAM & No Tracking & $0.08-0.011$ & $87-98$ \\
\hline
\end{tabular}

There is a gradual increase in the ac dielectric strength across the thickness of the composites due to the incorporation of nano fillers and their combination with micro fillers. The edge wise electric strength did not show differences due to the addition of nano and micro fillers. Improvement in dielectric strength due to nano- $\mathrm{SiO}_{2}$ filler is also reported by Q. Wang and co-authors [9]. But the incorporation of microfillers, helps to further improve the dielectric strength, though only marginally.

TABLE VII. AC DIELECTRIC STRENGTH (@50 Hz) OF THE COMPOSITES

\begin{tabular}{|l|l|l|}
\hline \multirow{2}{*}{ Composite } & \multicolumn{2}{|c|}{ Electric Strength $(\mathbf{k V} / \mathbf{m m})$} \\
\cline { 2 - 3 } & Flat wise & \multicolumn{1}{c|}{ Edgewise } \\
\hline GE & $20-22$ & Flashover observed at $60 \mathrm{kV}$ \\
\hline GESAA & $25-28$ & Withstood $60 \mathrm{kV}$ for $1 \mathrm{~min}$ \\
\hline GESAC & $27-30$ & Withstood $60 \mathrm{kV}$ for $1 \mathrm{~min}$ \\
\hline GESAM & $30-32$ & Withstood $60 \mathrm{kV}$ for $1 \mathrm{~min}$ \\
\hline
\end{tabular}

E. . SEM Analysis of composites after Electrical Breakdown Analysis of the SEM images of the composites after electric breakdown was undertaken and the images are shown in Figures 2(a-d). From SEM image of Figure 2a, the breakdown path in GE is observed to occur across ECR glass fibers and is dependent on the ability of the epoxy to bind the fibers together. It is observed from Figures 2(b-d) that the ECR glass fibers are well aligned and strongly bonded in case of GESAA, GESAC and GESAM in comparison to GE. The SEM image of GESAM composite after electrical breakdown confirms that GESAM undergoes reduced fiber breakage and the micro-structural architecture is retained with minimal damages, because of the better interfacial strength and fiber reinforcement supplemented by $\mathrm{MgO}$ filler.

\section{F. Dielectric Constant and Dissipation Factor}

The dielectric constant and dissipation factor of the composites were measured at $50 \mathrm{~Hz}$ and $2 \mathrm{kV}$. The values of dielectric constant and dissipation factor are shown in Table VIII. Only minor changes are observed in these parameters since the role of base epoxy with glass fiber reinforcement is 
more dominant than that of the fillers which are in small quantities [9-10].

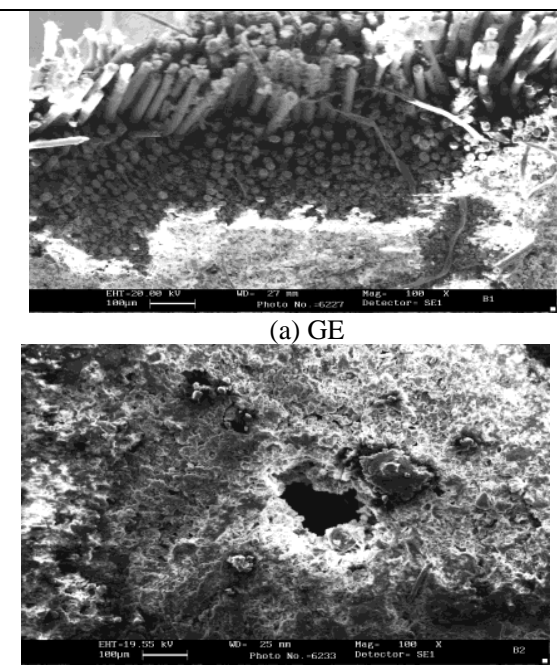

(b) GESAA

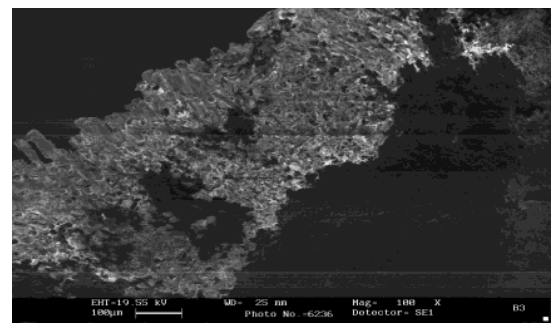

(c) GESAC

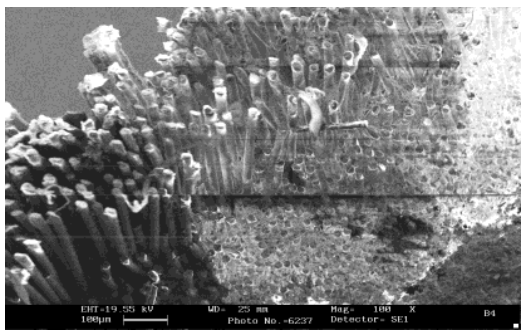

(d) GESAM

Fig 2. SEM images of GE, GESAA, GESAC and GESAM after electrical breakdown

TABLE VIII. DIELECTRIC CONSTANT AND TAN $\delta$ AT 2 KV

\begin{tabular}{|l|c|c|}
\hline Composite & $\begin{array}{c}\text { Dielectric } \\
\text { constant }\end{array}$ & Dissipation Factor \\
\hline GE & 4.0 & 0.027 \\
\hline GESAA & 3.9 & 0.035 \\
\hline GESAC & 3.9 & 0.026 \\
\hline GESAM & 3.8 & 0.037 \\
\hline
\end{tabular}

\section{G. Effect of fillers on volume and surface resistivity}

The results of volume resistivity of the composites in the as received condition and after $500 \mathrm{~h}$ immersion in water are shown in Table IX and Table $\mathrm{X}$ respectively. The composites with hybrid fillers incorporated show better volume and surface resistivity as compared to the base composite. Further, the reduction in volume resistivity or surface resistivity after immersion in water is relatively lower as compared to the base composites mainly due to the presence of fillers.
TABLE IX. VOLUME RESISTIVITY OF COMPOSITES UNDER DRY CONDITIONS AND AFTER WATER IMMERSION

\begin{tabular}{|c|c|c|}
\hline \multirow[b]{2}{*}{ Composite } & \multicolumn{2}{|c|}{ Volume Resistivity ( $\Omega$-cm) } \\
\hline & Dry condition & $\begin{array}{l}\text { After immersion in Water } \\
\text { for } 500 \mathrm{~h}\end{array}$ \\
\hline GE & $4 \times 10^{14}$ & $3.2 \times 10^{12}$ \\
\hline GESAA & $5 \times 10^{15}$ & $5.48 \times 10^{14}$ \\
\hline GESAC & $6 \times 10^{15}$ & $1.07 \times 10^{14}$ \\
\hline GESAM & $8 \times 10^{15}$ & $1.57 \quad 10^{14}$ \\
\hline
\end{tabular}

TABLE X. SURFACE RESISTIVITY OF VIRGIN AND WATER AGED COMPOSITES

\begin{tabular}{|c|c|c|}
\hline \multirow[b]{2}{*}{ Composite } & \multicolumn{2}{|c|}{ Surface Resistivity ( $\Omega /$ Square) } \\
\hline & Dry condition & $\begin{array}{c}\text { After immersion in Water } \\
\text { for } 500 \mathrm{~h}\end{array}$ \\
\hline GE & $7.68 \times 10^{13}$ & $7.68 \times 10^{13}$ \\
\hline GESAA & $9.86 \times 10^{13}$ & $9.86 \times 10^{13}$ \\
\hline GESAC & $12.3 \times 10^{13}$ & $12.3 \times 10^{13}$ \\
\hline GESAM & $13.5 \times 10^{13}$ & $13.5 \times 10^{13}$ \\
\hline
\end{tabular}

H. Impact of fillers on physico-mechanical properties Role of hybrid filler on Density and microstructure

The role of fillers on the density of the composites can be understood from the results of composites shown in Table XI. The differences in density due to incorporation of a mono nano-filler, combination of two nano-fillers and combination of two nano and one micro-filler is evident from the results of the table. In this table, the results of theoretical density computed based on the law of mixtures is compared with the experimentally measured values. The differences in the two are minimal and it is attributed to the presence of voids. Hence, the void fraction can be estimated as the ratio of the of measured density to the theoretical density, in percentage. It is observed that the volume fraction of voids in the composites decreases due to the incorporation of hybrid fillers.

TABLE XI. THEORETICAL AND MEASURED DENSITY AND VOLUME FRACTION OF VOIDS OF THE COMPOSITES

\begin{tabular}{|l|l|l|l|}
\hline Composite & $\begin{array}{c}\text { Theoreti } \\
\text { cal } \\
\text { density } \\
\left(\mathbf{g} / \mathbf{c m}^{\mathbf{3}}\right)\end{array}$ & $\begin{array}{c}\text { Measured } \\
\text { density } \\
\left(\mathbf{g} / \mathbf{c m}^{\mathbf{3}}\right)\end{array}$ & $\begin{array}{c}\text { Volume } \\
\text { fraction of } \\
\text { voids }(\boldsymbol{\%})\end{array}$ \\
\hline GE & 2.03 & 2.00 & 1.48 \\
\hline GEA & 2.10 & 2.07 & 1.43 \\
\hline GESA & 2.24 & 2.21 & 1.34 \\
\hline GESAA & 2.25 & 2.22 & 0.89 \\
\hline
\end{tabular}

\section{(i) Effect of fillers on the Hardness of the Composites}

The influence of hybrid fillers on the hardness (Shore-D) of composites can be seen from the data shown in Table XII. It is observed that the hardness of the composites increases with the addition of hybrid fillers because they impart better adhesion and cross linking of the fibers by the base epoxy. An increase of about $8 \%$ in hardness is seen in as compared to that of the base GE. Another reason for the increase, is the uniform dispersion of fillers in the epoxy matrix. The surface functionalized ECR-glass fiber provides better bonding of the epoxy matrix and the fillers due to improvement in its wetting by the epoxy resin. This helps in reducing the stress concentration across the fibers. From the study of 
morphology of GEASM, it is evident that the ECR-glass fibers are well embedded in the epoxy and its adherence to the fillers is relatively better. The good interfacial bonding is thus responsible for transfer of load to the ECR-glass fiber the fillers in the epoxy matrix, leading to better filler-filler interactions and the reduction in volume of voids or void fraction. These factors help in transfer of load from the matrix to the filler. Further, hardness depends on glass reinforcement of the composite, the effect of hybridization of fiber reinforcement and the level of cross-linking [3] [11-12]. The presence of hard ceramic filler in GEASM tends to increase the hardness.

\section{TABLE XII. RANGE OF HARDNESS (SHORE D) OF THE COMPOSITES}

\begin{tabular}{|l|c|}
\hline \multicolumn{1}{|c|}{ Composite } & Range of Hardness \\
\hline GE & $88-91$ \\
\hline GESAA & $90-93$ \\
\hline GESAC & $93-96$ \\
\hline GESAM & $95-97$ \\
\hline
\end{tabular}

(ii) Impact of fillers on the Tensile Strength

Evaluation of tensile strength of the composites would give a better understanding of the influence of fillers. The increase in the tensile strength and tensile modulus of the composites are shown in Fig. 3. There is a gradual increase of $10 \%$ in the tensile strength, due to the incorporation of fillers with a maximum increase is seen in GESAM. The increase in tensile strength as expected is within $10 \%$ since it is a fiberdependent property of the material [11-13]. The increase in tensile strength is partially attributed to additional loadbearing capability of the hybrid fillers. In GESAM, fillers nano-silica, nano-alumina and $\mathrm{MgO}$ are uniformly distributed and therefore the brittle nature of epoxy is compensated, and this leads to increase of the tensile strength. The tensile modulus also shows increase due to the addition of hybrid fillers. Similar results have been reported by some authors [3, 13], attributing the increase in tensile strength to higher glass fiber content, specific characteristics of the glass fiber and the glass fiber/matrix interface leading to greater restriction of molecular motion, stronger adhesion and higher energy dissipation at the interface.

\section{(iii) Effect fillers on the compression strength}

The compressive strength data of composites is shown in Fig. 4. The ECR glass fiber reinforced with hybrid fillers helps to improve the compressive strength by $7 \%$ to $24 \%$ in hybrid composites in comparison to the base GE.

Due to the combined nano- $\mathrm{Al}_{2} \mathrm{O}_{3}, \mathrm{SiO}_{2}$ and $\mathrm{CaCO}_{3}$ in GEASC, further improvement in compressive strength is observed. The lower void content of hybrid composites and the good adhesion between the fillers and the resin may be contributing to the improvement in the compressive strength as reported by some authors [11-13].

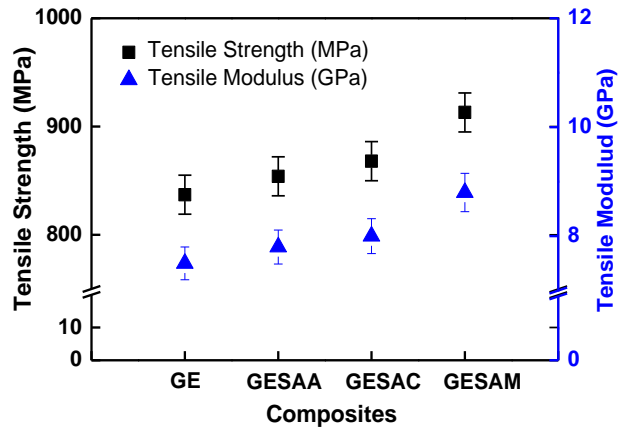

Fig. 3. Tensile strength and tensile modulus of the composites

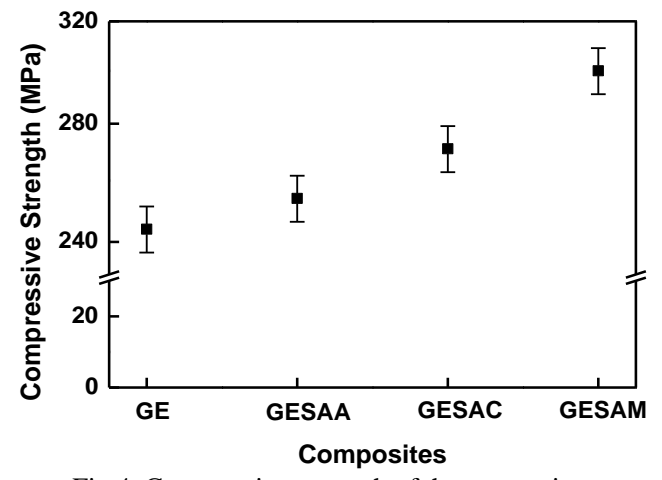

Fig 4. Compression strength of the composites

(iv) Dynamic mechanical analysis

The variations in the storage modulus of the composites with temperature is shown in Fig 5 and the Loss Modulus in Fig 6. The Storage modulus of GE and GESAA is observed to be $22500 \mathrm{MPa}$ but with the inclusion of $\mathrm{MgO}$ and $\mathrm{CaCO}_{3}$ fillers, the Storage modulus is reduced to $15000 \mathrm{MPa}$ in GESAC and $12500 \mathrm{MPa}$ in GESAM composites.

Similarly, the peak loss modulus decreases with incorporation of hybrid fillers. The loss modulus peak is $1900 \mathrm{MPa}$ in GE, and it is observed to be reduced to $1400 \mathrm{MPa}$ in GESAA, and $1200 \mathrm{MPa}$ in GESAC and $800 \mathrm{MPa}$ in GESAM. The loss modulus-temperature variations of hybrid the composites show the absence of two peaks which is observed in case of the base GE composite, due to removal of shorter segmental chains. Thus, hybrid fillers help in restricting the movement of shorter molecular chains. Based on the DMA analysis, assessment of the parameters like Cross-link density of fibers, fiber effectiveness and interfacial strength parameters were undertaken [14-15], and the results are shown in Tables XIII - XV. The results show that the cross-link density is the highest in GESAA, due to the presence of ATH filler. The effectiveness of fiber is highest due to the presence of $\mathrm{CaCO}_{3}$ in GESAC, followed by GESAM 


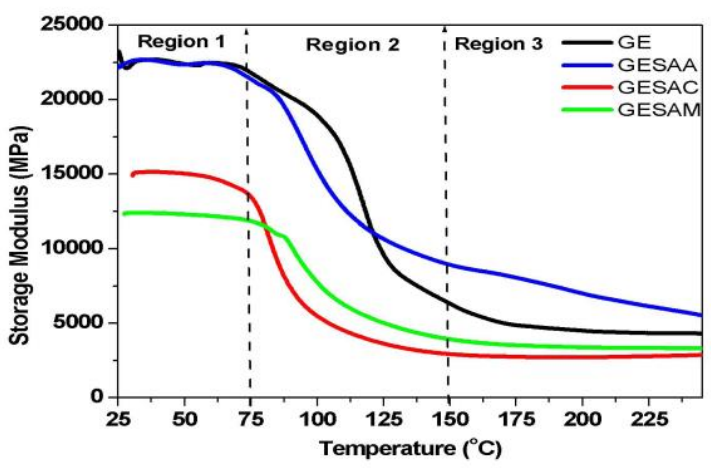

Fig. 5 Variations in Storage Modulus of the composites as a function of temperature

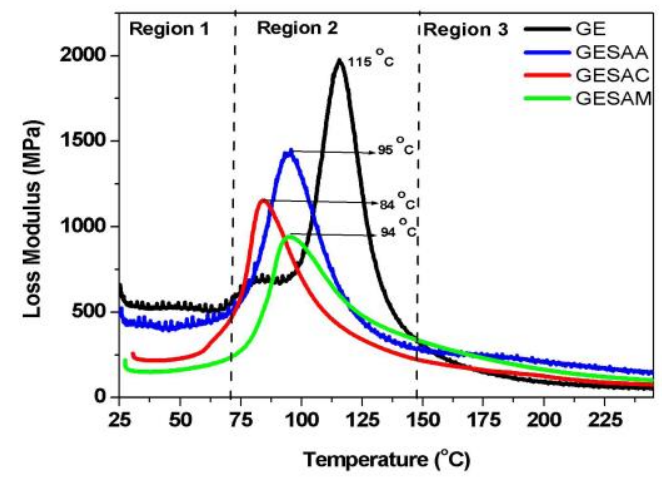

Figure 6. Variations in Loss Modulus of the composites as a function of temperature

TABLE XIII. CROSS-LINK DENSITY OF THE COMPOSITES

\begin{tabular}{|l|c|}
\hline \multicolumn{1}{|c|}{ Composite } & Cross-link density in $\mathbf{~ m o l} / \mathbf{c m}^{\mathbf{3}}$ \\
\hline GE & 2.825186 \\
\hline GESAA & 3.834181 \\
\hline GESAC & 1.291514 \\
\hline GESAM & 1.816191 \\
\hline
\end{tabular}

TABLE XIV. EFFECTIVENESS OF REINFORCEMENT

\begin{tabular}{|l|c|}
\multicolumn{1}{c}{ IN THE COMPOSITES } \\
\hline Composite & $\begin{array}{c}\text { Effectiveness } \\
\text { of reinforcement }\end{array}$ \\
\hline GE & 3.0 \\
\hline GESAA & 1.57 \\
\hline GESAC & 4.0 \\
\hline GESAM & 2.08 \\
\hline
\end{tabular}

TABLE XV. INTERFACIAL STRENGTH OF THE COMPOSITES

\begin{tabular}{|l|c|}
\hline \multicolumn{1}{|c|}{ Composite } & Interfacial strength \\
\hline GE & -1.612903226 \\
\hline GESAA & -1.720430108 \\
\hline GESAC & -1.935483871 \\
\hline GESAM & -2.258064516 \\
\hline
\end{tabular}

The increase in crosslink-density of GESAA points towards the fact that ATH fillers with $2.5 \mu \mathrm{m}$ diameter helps to improve the cross-link density but the 5 and $8 \mu \mathrm{m}$ particle size of $\mathrm{CaCO}_{3}$ and $\mathrm{MgO}$, leads to reduction in the cross-link density. The effectiveness of fibers is seen to be influenced by the presence of $\mathrm{CaCO}_{3}$ to the maximum extent. Further, the interfacial strength is observed to increase with incorporation of micro-fillers, with $\mathrm{MgO}$ having relatively the highest interfacial strength.

\section{CONCLUSIONS}

Some of the important conclusions of this study are the following

i) Proper selection of micro and nano fillers based on their properties is crucial for achieving balance of electrical and mechanical properties.

ii) Functionalization of glass fiber and nano fillers helps to improve fiber matrix interactions while the micro fillers help in improving the interfacial strength.

iii) Water absorption and desorption is an epoxy dependent characteristic and the incorporation of hybrid fillers is beneficial in terms of enhancement of $\mathrm{CA}$, in-addition to improvement in electrical and mechanical strength.

iv) Density variations depend on the combination of nano and micro-fillers. The void volume fraction also decreases with combination of micro and nano filers.

v) The tensile strength and the compressive strength improve by 9 to $23 \%$ and storage modulus by $56 \%$ and a 20 to 40 $\%$ reduction in loss modulus are observed due to the addition of nano and micro fillers.

vi) In GESAM, $\mathrm{MgO}$ filler helps in reducing the damage caused to the fiber during electrical breakdown and thus better electrical properties accrue due to inclusion of micron sized $\mathrm{MgO}$ filler.

vii) The size of the micro-filler particle is crucial, and it determines the extent of water that can occupy the free volume of the hybrid composites. GESAM appears to be relatively better in this aspect, followed by GESAC.

viii) The water zone model which is a characteristic of a nano composite is essentially determined by the way the nano and micro-fillers are distributed within the epoxy matrix.

ix) GESAM undergoes reduced fiber breakage and the microstructural architecture is retained with minimal damages, under electrical breakdown because of the good interfacial strength and reasonably good fiber reinforcement which is supplemented by the presence of the $\mathrm{MgO}$ filler.

\section{REFERENCES}

[1] Minh-Tai Le and Shyh-Chour Huang (2015) "Thermal and mechanical behavior of hybrid polymer nanocomposite reinforced with graphene nanoplatelets.” Materials, 8, 5526-5536.

[2] J.C. Fothergill, J.K. Nelson and M. Fu. (2004) "Dielectric properties of epoxy nanocomposites containing $\mathrm{TiO}_{2}, \mathrm{Al}_{2} \mathrm{O}_{3}$ and $\mathrm{ZnO}$ fillers." IEEE Conf. Electr. Insul. Dielectr phenomena (CEIDP), 406-409.

[3] Heitor Luiz Ornaghi Jr, Humberto Sartori Pompeo da Silva, Ademir Jose Zatterab and Sandro Campos Amicoa. (2011) "Hybridization effect on the mechanical and dynamic mechanical properties of curaua composites.” Mat. Sci. Eng., 528, 7285-7289.

[4] Edison E. Haro, Akindele G. Odeshi and Jerzy A. Szpunar. (2018) "The effects of micro- and nano-fillers' additions on the dynamic impact response of hybrid composite armors made of HDPE reinforced with Kevlar Short Fibers.” Polym-Plast Technol. Eng., 57, 609-624.

[5] Shanty P Kuruvilla, N M Renukappa and J. Sundara Rajan. (2018) "Development of epoxy with nano and micro fillers for core insulation of composite insulators." IEEE Int. Conf. High Voltage Eng. Technol (ICHVET), Hyderabad, India. 
[6] M. Suchitra, N. M. Renukappa, C. Ranganathiah, T. Pasang and J. Sundara Rajan. (2016). "Moisture and filler induced effects on the dynamic mechanical properties of glass fiber reinforced epoxy hybrid composites.” IEEE Trans. Dielectr. Electr. Insul. 23, 6, 3631-3640.

[7] M. Suchitra, N. M. Renukappa, C. Ranganathaiah and J. Sundara Rajan. (2018) "Correlation of free space length and surface energy of nanocomposites to surface tracking." IEEE Trans. Dielectr. Electr. Insul. 25, 6, 2129-2138.

[8] S. Singha, and M.J. Thomas. (2008) "Dielectric properties of epoxy nanocomposites.” IEEE Trans. Dielectr. Electr. Insul. 15, 1, 12-23.

[9] Parimal Maity, Subramanyam V Kasisomayajula, Venkitanarayanan Parameswaran, Sumit Basu and Nandini Gupta. (2008) "Improvement in surface degradation properties of polymer composites due to preprocessed nanometric alumina fillers." IEEE Trans. Dielectr. Electr. Insul., 15, 1, 68-72

[10] Q. Wang and G. Chen. (2014) "Effect of pre-treatment of nanofillers on the dielectric properties of epoxy nanocomposites." IEEE Trans. Dielectr. Electr. Insul., 21, 4, 1809-1815.

[11] Daiane Romanzini, Alessandra Lavoratti, Heitor L. Ornaghi Jr, Sandro C. Amico and Ademir J. Zattera. (2013) "Influence of fiber content on the mechanical and dynamic mechanical properties of glass/ramie polymer composites." Materials and Design, 47, 9-15.

[12] K. Sai Sravani, B. Ram Gopal Reddy, Raffi Mohammed. (2017) "Effect of $\mathrm{CaCO}_{3}$ and $\mathrm{Al}_{2} \mathrm{O}_{3}$ fillers on mechanical properties of glass/epoxy composites.” Int. J Mod. Trends. Sci. Technol. 3, 6, 207-214.

[13] M Manjunath, N M Renukappa and B Suresha. (2016) "Influence of micro and nanofillers on mechanical properties of pultruded unidirectional glass fiber reinforced epoxy composite systems." J compos. Mater., 50, 8, 1109-1121.

[14] Jiaming Yang, Xuan Wang, Hong Zhao, Wenlong Zhang and Mingzhong Xu. (2014) "Influence of moisture absorption on the DC conduction and space charge property of $\mathrm{MgO} / \mathrm{LDPE}$ nanocomposite." IEEE Trans. Dielectr. Electr. Insul., 21, 4, 1957-1964.

[15] Chang-Hoon Lee and Jae-Jun Park. (2010) "The properties of DSC and DMA for epoxy nano-and-micro mixture composites." Trans. Electr. Electro. Mater. 11,69-72. 